\title{
Human Neutrophils Contain and Bind High Molecular Weight Kininogen
}

\author{
Ellen J. Gustafson, Alvin H. Schmaier, Yanina T. Wachtfogel, Nathan Kaufman, Umberto Kucich,* and Robert W. Colman \\ Department of Medicine and the Thrombosis Research Center, Temple University School of Medicine, \\ Philadelphia, Pennsylvania 19140; and *Research Division, Department of Medicine, The Graduate Hospital, \\ Philadelphia, Pennsylvania 19146
}

\begin{abstract}
Because plasma kallikrein activates human neutrophils, and in plasma prekallikrein (PK) circulates complexed with high molecular weight kininogen (HMWK), we determined whether HMWK could mediate kallikrein's association with neutrophils. HMWK antigen (237 \pm 61 ng $H M W K / 10^{8}$ neutrophils) was present in lysates of washed human neutrophils. Little if any plasma HMWK was tightly bound and nonexchangeable with the neutrophil surface. Human neutrophils were found to possess surface membrane-binding sites for HMWK but no internalization was detected at $37^{\circ} \mathrm{C} .{ }^{125} \mathrm{I}-\mathrm{HMWK}$ binding to neutrophils was dependent upon $\mathrm{Zn}^{2+}$. Binding of ${ }^{125} \mathrm{I}-\mathrm{HMWK}$ to neutrophils was specific and $90 \%$ reversible. ${ }^{125} \mathrm{I}-\mathrm{HMWK}$ binding to neutrophils was saturable with an apparent $\boldsymbol{K}_{\mathrm{d}}$ of 9-18 $\mathrm{nM}$ and 40,000-70,000 sites per cell. Upon binding to neutrophils, ${ }^{125}$ I-HMWK was proteolyzed by human neutrophil elastase (HNE) into lower relative molecular mass derivatives. Furthermore, HMWK found in neutrophils also served as a cofactor for HNE secretion because neutrophils deficient in HMWK have reduced HNE secretion when stimulated in plasma deficient in HMWK or with purified kallikrein. These studies indicate that human neutrophils contain a binding site for HMWK that could serve to localize plasma or neutrophil HMWK on their surface to possibly serve as a receptor for kallikrein and to participate in HNE secretion by this enzyme.
\end{abstract}

\section{Introduction}

High molecular weight kininogen (HMWK) ${ }^{1}$ serves as a cofactor in the activation of the zymogen plasma kallikrein (PK) (1). In plasma, PK is a zymogen that circulates in a noncovalent complex with HMWK $(2,3)$. The binding of HMWK to negatively charged surfaces enables PK to attach to negatively charged surfaces where the zymogen can be optimally activated to kallikrein by Factor XIIa $(4,5)$. Kallikrein expresses chemotactic (6), aggregating (7), and degranulating (8) activity with neutrophils. Other chemotactic factors for neutrophils such as FMLP (9) and C5a (10), have been shown to have

Address reprint requests to Robert W. Colman, Thrombosis Research Center, Temple University School of Medicine, 3400 North Broad Street, Philadelphia, PA 19140.

Received for publication 20 January 1988 and in revised form 27 February 1989.

1. Abbreviations used in this paper: FDNPS, fibrinogen degradation products; HMWK, high molecular weight kininogen; HNE, human neutrophil elastase; PK, prekallikrein.

J. Clin. Invest.

(c) The American Society for Clinical Investigation, Inc. 0021-9738/89/07/0028/08 \$2.00

Volume 84 , July $1989,28-35$ specific binding sites on neutrophils. The receptor(s) for plasma kallikrein on neutrophils is not known.

Although receptors are frequently integral membrane proteins, at least one enzyme Factor Xa binds to a cell (platelet) through an "acquired receptor," the plasma cofactor Factor Va (11). We postulated that kallikrein might bind to neutrophils through its cofactor, HMWK, with which it complexes. Platelets have been shown to contain a form of HMWK (12, 13), which can be expressed on the activated platelet surface (14). As HMWK has been shown to bind to activated (15) and unstimulated (16) platelets, studies were initiated to determine if neutrophils also contain a form of HMWK and whether the external membrane of human neutrophils possesses a specific binding site for HMWK. The results of this investigation demonstrate that neutrophils contain HMWK and possess a specific, reversible, and saturable binding site for HMWK. Furthermore, HMWK from either plasma or neutrophils is a cofactor for HNE secretion.

\section{Methods}

Materials. Iodogen (chloramide, 1,3,4,6-tetrachloro-3 alpha, 6 alphadiphenylglycoluril) was obtained from Pierce Chemical Co., Rockford, IL. ${ }^{125} \mathrm{I}-\mathrm{Na}$ ( $50 \mathrm{mCi} / \mathrm{mmol}$ ) was obtained from ICN Pharmaceuticals, Irvine, CA. $N$-Butyl-phthalate was obtained from Fisher Scientific Co., Pittsburgh, PA. Apiezion oil (a mixture of silicon oils) was obtained from Apiezion Products Limited, London, England. HBSS free of calcium chloride, magnesium sulfate, and magnesium chloride was obtained from Gibco Laboratories, Grand Island, NY. Ficoll-Hyaque was obtained from Pharmacia Fine Chemicals, Piscataway, NJ.

Plasma and neutrophils. Pooled normal plasma (lot 6130) was purchased from George King Biomedical Inc., Overland Park, KS. Total kininogen-deficient plasma (plasma deficient in both HMWK and low molecular weight kininogen) and neutrophils deficient in HMWK were donated by Mrs. Mayme Williams. Normal donors were young males and females (age $21-45 \mathrm{yr}$ ) receiving no medication, who had given their written, informed consent.

Neutrophil isolation. Human neutrophils were isolated from whole blood anticoagulated with one-tenth volume acid-citrate-dextrose by sedimentation at $1 \mathrm{~g}$ in dextran (1.5\%). After sedimentation, the upper leukocyte-enriched plasma was gently layered over $15 \mathrm{ml}$ of FicollHyaque (each $100 \mathrm{ml}$ contains $5.7 \mathrm{~g}$. Ficoll 400 and $9.0 \mathrm{~g}$ sodium ditrizoate sodium) and centrifuged at $400 \mathrm{~g}$ for $30 \mathrm{~min}$ at $23^{\circ} \mathrm{C}$. The cell pellet was resuspended in an erythrocyte lysis buffer composed of $155 \mathrm{mM} \mathrm{NH}_{4} \mathrm{Cl}, 2.7 \mathrm{mM} \mathrm{KHCO}_{3}$, and $3.7 \mathrm{mM}$ EDTA. The suspension was centrifuged at $400 \mathrm{~g}$ for $20 \mathrm{~min}$ and the cell pellet was washed three times in excess saline, $\mathrm{pH}$ 7.4. After the final saline wash, the cells were resuspended in HBSS without magnesium or calcium (1 $\times 10^{7}-10^{9}$ cells $/ \mathrm{ml}$ ). Cell count and purity were determined after dilution in Turk's solution (3\% glacial acetic acid and $1 \%$ crystal violet). This procedure yielded $\sim 8 \times 10^{8}$ neutrophils/unit whole blood and the cells were isolated to $96 \%$ purity. The number of platelets per neutrophil averaged 5 per 100 (range 3 to 8). The cells were either solubilized with $0.5 \%$ Triton $\mathrm{X}-100$ (final concentration) and stored at $-70^{\circ} \mathrm{C}$ for antigen determination or used immediately in binding experiments. 
Proteins. HMWK was purified using a modified method (14) of Kerbiriou and Griffin (17). Under reducing conditions, this preparation of HMWK appeared on a 7.5\% SDS-polyacrylamide gel (18) as primarily a single $120,000-k D$ band with $>98 \%$ purity and a specific activity of 12-20 U/ml. Purified HMWK was radiolabeled with ${ }^{125} \mathrm{I}-\mathrm{Na}$ using Iodogen by the method of Fraker and Speck (19) under conditions previously described (16). The specific radioactivity of the protein varied from $1-3.5 \mu \mathrm{Ci} / \mu \mathrm{g}$ and $>75 \%$ of the molecules of $\mathrm{HMWK}$ being iodinated. The radiolabeled protein retained $>95 \%$ of its procoagulant activity as well as its antigenic properties as previously reported (16).

Purified Factor XII (70 $\mu \mathrm{g} / \mathrm{ml})$, PK $(1 \mathrm{mg} / \mathrm{ml})$, and $\alpha_{1}$-antiprotease inhibitor were provided by Dr. Robin Pixley; fibronectin degradation products (FNDPs) $(1.3 \mathrm{mg} / \mathrm{ml})$ were donated by Dr. Andrei Budzynski, and Factor $\mathrm{V}$ was donated $(0.93 \mathrm{mg} / \mathrm{ml})$ by Dr. Angie Annamalai, all of Temple University, Philadelphia, PA. Foy, a specific inhibitor of cathepsin $G(20)$ and a monospecific polyclonal antibody to HNE (21), were generously provided by Dr. Fred Kueppers, Temple University, Philadelphia, PA. Eglin, an inhibitor of cathepsin G and HNE, was generously provided by Dr. Hans-Peter Schnebli, CibaGeigy AG, Basel, Switzerland. HNE was purified to homogeneity by the procedure of Baugh and Travis (22).

Assays. HMWK procoagulant activity was measured by a onestage kaolin activation assay (23) using total kininogen-deficient plasma as substrate. Samples were compared with a simultaneously performed standard curve from pooled normal human plasma diluted one-tenth to one-thousandth with $0.01 \mathrm{M}$ Tris, $0.15 \mathrm{M} \mathrm{NaCl}, \mathrm{pH}$ 7.4. One unit was defined as that amount of procoagulant activity in $1 \mathrm{ml}$ of pooled normal plasma. HMWK antigen was measured by a competitive ELISA, performed as previously reported (12) using a monospecific polyclonal antibody directed to the 56-kD light chain of HMWK (12). HNE activity was measured by a chromogenic assay using the substrate, methoxysuccinyl-Ala-Ala-Pro-Val-pNA (24) and antigenic levels were measured using a competitive ELISA specific for HNE (8). Cathepsin $G$ activity was measured using the spectrophotometric assay described by Barrett (25). Lactic dehydrogenase loss from washed neutrophils was measured by the procedure of Wroblewski and Ladue (26).

Neutrophil aggregation. Aggregation was performed with modifications of the previously described method $(7) \div$ Neutrophils $\left(1 \times 10^{7} / \mathrm{ml}\right)$ were resuspended in a total volume of $1 \mathrm{mLHBSS}$ containing a final concentration of $2 \mathrm{mM} \mathrm{CaCl}_{2}, 1.5 \mathrm{mM} \mathrm{MgCl}_{2}$, and $5 \mu \mathrm{g}$ cytochlasin B in the presence of agonist. Aggregation was measured using a platelet aggregometer (Monitor IV Plus, Helena Laboratories, Beaumont, TX) revolving at $900 \mathrm{rpm}$.

Neutrophil degranulation in an in vitro plasma-free system. Supernatants were harvested for subsequent $\mathrm{HNE}$ activity determinations by centrifuging the contents of the aggregation cuvettes at $13,000 \mathrm{~g}$ for 5 min at $23^{\circ} \mathrm{C}$ in a microcentrifuge (model 235A; Fisher Scientific Co.). The supernatants were assayed using the chromogenic substrate methoxysuccinyl-Ala-Ala-Pro-Val-PNA (8).

Neutrophil degranulation in an in vitro plasma system. Neutrophils $\left(1 \times 10^{7} / \mathrm{ml}\right)$ were resuspended in polypropylene tubes containing plasma whereupon $\mathrm{Ca}^{2+}$ (final concentration $30 \mathrm{mM}$ ) was added. Incubations were performed for various times at $23^{\circ} \mathrm{C}$, and aliquots were then removed and centrifuged at $13,000 \mathrm{~g}$ for $5 \mathrm{~min}$ at $23^{\circ} \mathrm{C}$ in a microcentrifuge. The plasma supernatants were stored at $-70^{\circ} \mathrm{C}$ until immunochemical determinations of elastase were made, using an indirect competitive ELISA $(8,33)$.

Binding experiments. In all binding experiments neutrophils were at a final concentration of $1 \times 10^{7} / \mathrm{ml}$. In a typical binding experiment $300-400 \mu \mathrm{l}$ of washed neutrophils in HBSS without added calcium or magnesium, $\mathrm{pH} 7.4$, were incubated at $23^{\circ} \mathrm{C}$, without stirring in a 1.5-ml conical polypropylene centrifuge tube (Sarstedt, Inc., Princeton, NJ) with ${ }^{125} \mathrm{I}-\mathrm{HMWK}$ and additions to a total volume of 350-450 $\mu l$ were made. After incubation of appropriately expanded volumes, $50-\mu$ aliquots were removed (in triplicate) for each experimental point and centrifuged at $9,650 \mathrm{~g}$ at $23^{\circ} \mathrm{C}$ in a microfuge (model B; Beckman
Instruments, Inc., Fullerton, CA) through a 200- $\mu$ l mixture of silicon oils (one part Apiezion/nine parts $N$-butyl-phthalate) in polypropylene microsedimentation tubes with narrow bore extended tips (Sarstedt, Inc., Princeton, NJ) for $2 \mathrm{~min}$. After the supernatant was removed, the tips containing the pellet were amputated and counted in a gamma counter (Rack; LKB Instruments, Inc., Gaithersburg, MD).

Detection of HMWK on the surface of washed neutrophils. Detection of the amount of neutrophil HMWK on the surface of the neutrophil was performed by a competitive ELISA developed for measuring surface HMWK on platelets (19) and modified for neutrophils. The neutrophil samples were prepared for use in a modified competitive ELISA for HMWK as an indirect antibody consumption assay. Conditions for this antibody consumption assay for surface-expressed neutrophil HMWK were developed so that intraneutrophil HMWK (that which was neither secreted nor expressed on the external membrane) would not interfere. Four samples were prepared: $(a)$ suspension of neutrophils; $(b)$ suspension buffer from pelleted neutrophils; $(c)$ buffer alone (negative control); and (d) buffer containing $200 \mathrm{ng} / \mathrm{ml} \mathrm{HMWK}$ (positive control). Each specimen was mixed with an equal volume of monospecific anti-HMWK antisera (final concentration 1:500). This antisera had previously been diluted 1:250 in $0.01 \mathrm{~mol} /$ liter HBSS and was also made 1:250 with total kininogen deficient plasma. Before the prepared antisera was mixed with the neutrophil material, the antisera was ultracentrifuged at $100,000 \mathrm{~g}$ for $90 \mathrm{~min}$ in a ultracentrifuge (model L3-50, Beckman Instruments, Inc.) to remove any aggregates that might be present. The total kininogen-deficient plasma was added to the incubation mixture to prevent nonspecific association of goat anti-HMWK IgG to human neutrophil Fc receptors by the addition of excess human IgG. After the four neutrophil samples were combined with the antisera, each mixture was incubated for $1 \mathrm{~h}$ at $37^{\circ} \mathrm{C}$. At completion of the incubation, each specimen was centrifuged at 12,000 $g$ in a microcentrifuge, and the supernatants were collected.

Four antibody samples per experiment were then compared by a competitive ELISA assay for HMWK (19) using known amounts of purified HMWK antigen to determine the slope of the competitive inhibition curve produced by each. The competitive inhibition curves generated on the competitive ELISA by the four aliquots of adsorbed antisera were produced by the method of incubation of samples as previously reported (19). However, because the aim of the assay was to determine whether the titer of the antisera would be decreased (consumed) by incubation with neutrophils or their supernatants, the final competitive inhibition curves were analyzed by linear regression to determine the slope of the competitive inhibition curve produced by antisera adsorbed with each of the aliquots of neutrophil material. In all experiments, the differently adsorbed aliquots of antisera were reacted with the same amounts of purified HMWK (1-125 ng). The measured value of this assay was the slope of the competitive inhibition curve.

Statistical analysis. Calculation of bound HMWK was based on the specific activities of the radiolabeled ligand, and the results were expressed as nanograms of HMWK per $10^{7}$ neutrophils. In a typical experiment, total binding was the amount of ${ }^{125} \mathrm{I}-\mathrm{HMWK}$ bound in the absence of unlabeled ligand, while nonspecific binding was the amount of ${ }^{125} \mathrm{I}$-HMWK bound in the presence of a 50 -fold molar excess of unlabeled ligand. Specific binding was obtained by subtracting the nonspecific binding from the total binding.

In competition inhibition experiments with unlabeled HMWK, the affinity of binding of ${ }^{125} \mathrm{I}-\mathrm{HMWK}$ was calculated from the $\mathrm{IC}_{50}(27)$ as previously reported $(16,28)$ using a computer program to determine the $50 \%$ inhibition point (29). In concentration-dependent experiments, binding ${ }^{125} \mathrm{I}-\mathrm{HMWK}$ to PMNs was also analyzed by the graphical methods of Scatchard (30), as well as the computer programs of Munson and Rodbard (31) and Brass and Shattil (32) using an Apple Ile Computer (Apple Computer Corp., Cupertino, CA). Experimental results at each concentration of the total dose of ligand (both labeled and unlabeled) and bound radioligand were fed into a preanalysis program (31). After calculating the amount of specifically bound ligand the data were also fit by the program developed by Brass (32). 
Comparison of the differences of experimental groups in the binding studies were performed by the $t$ test (paired). Significant differences are defined as $P<0.05$. All values are expressed as mean \pm SEM.

\section{Results}

Identification of neutrophil HMWK. To delineate how HMWK may interact with neutrophils, studies were first performed to determine if washed human neutrophils contain associated HMWK antigen (Fig. 1). Washed solubilized neutrophils from normal blood donors were found to have $237 \pm 61 \mathrm{ng} H M W K$ antigen $/ 10^{8}$ cells (mean \pm SEM, $n=8$ ). This result was specific for the identification of HMWK antigen because a lysate of neutrophils from a patient with a known total deficiency of plasma and platelet $\operatorname{HMWK}(12,23)$ had a neutrophil HMWK value of $\leq 2.7 \mathrm{ng} / 10^{8}$ cells (Fig. 1). Neutrophil HMWK was immunochemically identical to plasma HMWK, as indicated by parallel competition inhibition curves produced on a competitive ELISA (data not shown).

Detection of HMWK on the surface of washed neutrophils. Neutrophils, their supernatants, and controls were incubated with antiserum directed against the light chain of HMWK to determine if neutrophil HMWK was HMWK derived from plasma bound to this cell's surface. The competitive inhibition curves (Fig. 2) produced by antisera adsorbed with the supernatants of neutrophils (slope $=0.34$ ), neutrophils (slope $=0.36$ ), and buffer (slope $=0.39$ ) were almost superimposable. As expected, the competitive inhibition curve produced by antisera adsorbed with purified HMWK $(200 \mathrm{ng} / \mathrm{ml}$ final concentration) was decreased significantly (slope $=0.23$ ). Thus plasma HMWK, having been easily washed off, was not tightly bound to the neutrophil surface and did not greatly contribute to the content of neutrophil HMWK.

Binding of ${ }^{125}$ I-labeled HMWK to isolated neutrophils. Further investigations were conducted to ascertain whether the external membrane of neutrophils contained unoccupied binding sites for HMWK. Binding experiments of ${ }^{125} \mathrm{I}$-HMWK to washed neutrophils were performed at 4,23 , and $37^{\circ} \mathrm{C}$. Neutrophils bound ${ }^{125} \mathrm{I}-\mathrm{HMWK}$ at all temperatures and the amount of ${ }^{125}$ I-HMWK bound was equivalent at all temperatures (Fig. 3). Approximately $90 \mathrm{ng}$ of ${ }^{125} \mathrm{I}-\mathrm{HMWK} / 10^{7} \mathrm{neu}-$ trophils were bound at the plateau of binding which was reached by 15-20 min at all temperatures. Nonspecific binding, which was determined by binding of ${ }^{125} \mathrm{I}-\mathrm{HMWK}$ in the

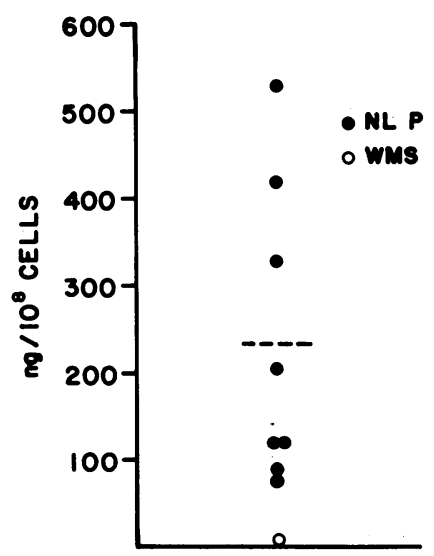

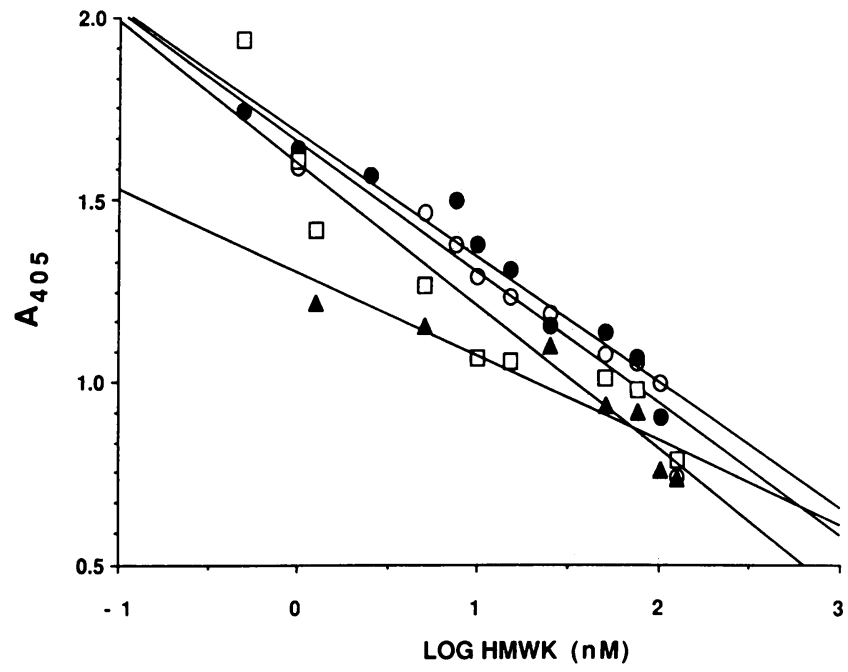

Figure 2. Detection of HMWK on the surface of washed neutrophils. The competitive inhibition curves produced by antiserum directed against the light chain of HMWK adsorbed with neutrophils (0),

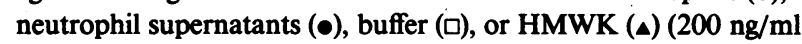
final concentration) are plotted versus $\log H M W K$ concentration.

presence of a 50-fold molar excess of unlabeled HMWK, was $\sim 15 \%$ of total binding. ${ }^{125}$ I-HMWK bound to neutrophils regardless of whether the PMNs were metabolically intact or incubated with leupeptin $(100 \mu \mathrm{M})$ or soybean trypsin inhibitor $(100 \mu \mathrm{M})$. This experiment along with that in Fig. 2 indicated that HMWK antigen in neutrophils was not internalized from plasma.

Subsequent investigations determined the divalent cation requirements for binding of ${ }^{125} \mathrm{I}$-HMWK to neutrophils (Fig. 4): As $\mathrm{Zn}^{2+}$ is an absolute divalent cation requirement for the binding of ${ }^{125} \mathrm{I}-\mathrm{HMWK}$ to platelets (16), its contribution to the binding with neutrophils was investigated. In the presence of $50 \mu \mathrm{M} \mathrm{Zn}^{2+}$, binding of ${ }^{125} \mathrm{I}-\mathrm{HMWK}$ to neutrophils increased over time to reach a plateau by $15 \mathrm{~min}$. The amount of ${ }^{125} \mathrm{I}$ HMWK bound in the presence of $2 \mathrm{mM} \mathrm{Ca}^{2+}$ or $2 \mathrm{mM} \mathrm{Mg}^{2+}$ was not significantly different from the level of nonspecific binding. Moreover, binding of ${ }^{125} \mathrm{I}-\mathrm{HMWK}$ in the presence of $\mathrm{Zn}^{2+}$ and $\mathrm{Ca}^{2+}$ or $\mathrm{Zn}^{2+}, \mathrm{Ca}^{2+}$ and $\mathrm{Mg}^{2+}$ resulted in a level of binding that was not significantly different $(P \geq 0.45)$ from the level of binding in the presence of $\mathrm{Zn}^{2+}$ alone, thus demonstrating that either $\mathrm{Ca}^{2+}$ or $\mathrm{Mg}^{2+}$ contributed nothing to the

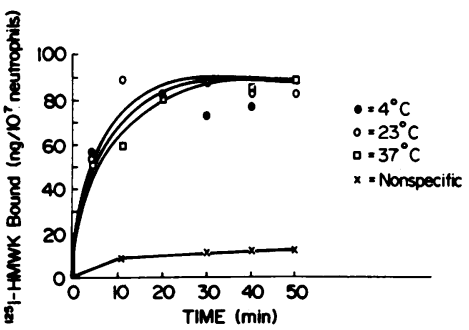

Figure 3. Binding of ${ }^{125} \mathrm{I}$ HMWK to neutrophils at various temperatures. Isolated PMNs $\left(1 \times 10^{7} / \mathrm{ml}\right)$ in $\mathrm{HBSS}$ without $\mathrm{Ca}^{2+}$ or $\mathrm{Mg}^{2+}$ but with $50 \mathrm{nM}$ $\mathrm{Zn}^{2+}$, pH 7.4, were incubated at $4^{\circ} \mathrm{C}(\bullet), 23^{\circ} \mathrm{C}(0)$, or $37^{\circ} \mathrm{C}(\square)$ with ${ }^{125} \mathrm{I}-$ HMWK $(1, \mu \mathrm{g} / \mathrm{ml})$ in the presence of $\mathrm{Zn}^{2+}(50 \mu \mathrm{M})$. Nonspecific binding (nonspecific) of ${ }^{125} \mathrm{I}$ HMWK was measured in the presence of $50 \mu \mathrm{M} \mathrm{Zn}^{2+}$ and a 50 -fold molar excess of unlabeled $\mathrm{HMWK}$ at $23^{\circ} \mathrm{C}(\mathrm{X})$. At the designated time points, samples were removed and the amount of ${ }^{125}$ I-HMWK bound to neutrophils was determined as indicated in Methods. The results are the mean of four separate experiments and the plotted data represent total binding. 


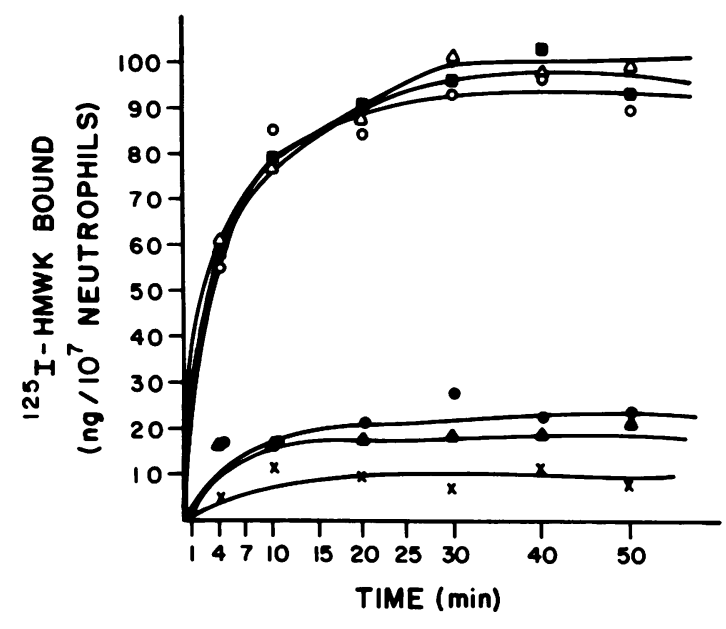

Figure 4. Effect of divalent cations on binding of ${ }^{125} \mathrm{I}-\mathrm{HMWK}$ to neutrophils. Isolated neutrophils $\left(1 \times 10^{7} / \mathrm{ml}\right)$ in HBSS without $\mathrm{Ca}^{2+}$ or $\mathrm{Mg}^{2+}$ were incubated at $37^{\circ} \mathrm{C}$ for $4-50 \mathrm{~min}$ with ${ }^{125} \mathrm{I}-\mathrm{HMWK}$ (1 $\mu \mathrm{g} / \mathrm{ml}$ ) and various cations. In each experiment where an addition was made, the concentration of $\mathrm{Zn}^{2+}$ was $50 \mu \mathrm{M}$ and $\mathrm{Ca}^{2+} 2 \mathrm{mM}$. At the designated time points, binding of ${ }^{125} \mathrm{I}$-HMWK to neutrophils was determined as indicated in Methods. Binding was determined in the presence of $\mathrm{Zn}^{2+}$ alone (0), $\mathrm{Zn}^{2+}$ and $\mathrm{Ca}^{2+}(\Delta), \mathrm{Zn}^{2+}, \mathrm{Ca}^{2+}$, and

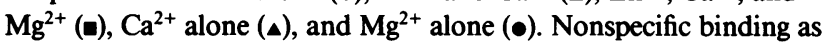
determined by radioligand binding in the presence of $\mathrm{Zn}^{2+}(50 \mu \mathrm{M})$ and a 50-fold molar excess of unlabeled HMWK $(X)$. The plotted data are the mean of four experiments and represent total binding. For clarity the SEMs are omitted, but they represent $\sim 10 \%$ of the mean.

binding of ${ }^{125} \mathrm{I}$-HMWK to neutrophils (Fig. 4). Therefore, $\mathrm{Zn}^{2+}$ was the only divalent cation tested required for binding of ${ }^{125}$ I-HMWK to neutrophils.

Specificity of binding of ${ }^{125} \mathrm{I}-\mathrm{HMWK}$ binding to neutrophils. To ascertain whether the binding of ${ }^{125} \mathrm{I}-\mathrm{HMWK}$ to neutrophils was specific, we first investigated the capacity of other proteins, besides unlabeled HMWK, to inhibit binding of ${ }^{125} \mathrm{I}$ HMWK to neutrophils (Table I). ${ }^{125}$ I-HMWK binding to neutrophils was not inhibited by a 50-100-fold molar excess of Factor V, Factor XII or PK, and only modestly by FNDPs.

Further studies were performed to insure that the interaction of HMWK with neutrophils was not influenced by the radioiodination of HMWK. Washed neutrophils were incu-

Table I. Specificity of Binding of ${ }^{125}$ I-HMWK to Neutrophils

\begin{tabular}{lc}
\hline \multicolumn{1}{c}{ Protein competitor } & \% Inhibition as a \% of control \\
\hline None & 0 \\
Unlabeled HMWK $(50)$ & 100 \\
Factor V $(50)$ & $10.5 \pm 2.4$ \\
Factor XII (50) & $13.0 \pm 1.8$ \\
Prekallikrein (100) & $1.0 \pm 1.8$ \\
FNDPs (50) & $22.0 \pm 2.3$ \\
\hline
\end{tabular}

${ }^{125} \mathrm{I}-\mathrm{HMWK}(1 \mu \mathrm{g} / \mathrm{ml})$ was incubated for $15 \mathrm{~min}$ at room temperature with human neutrophils $\left(5 \times 10^{6} / \mathrm{ml}\right)$ in HBSS in the presence of various proteins. Each competitor was added in the molar excess, which is given in parentheses. Values presented are the mean \pm SEM of three experiments.

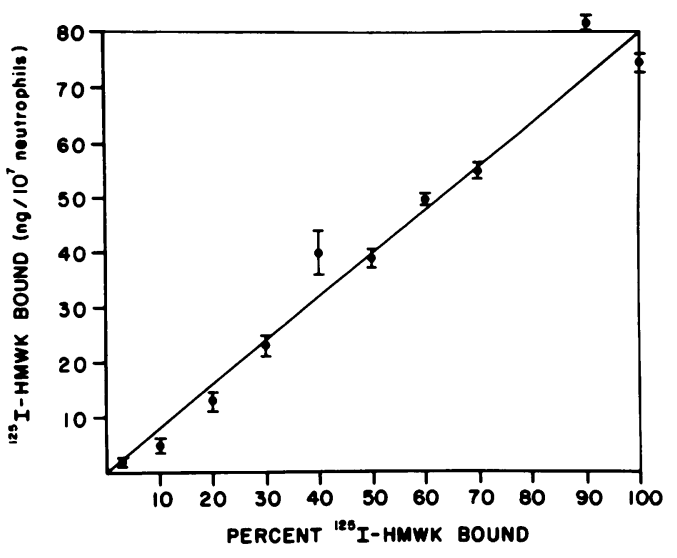

Figure 5. Relative binding of ${ }^{125} \mathrm{I}-\mathrm{HMWK}$ and unlabeled HMWK to neutrophils. Isolated neutrophils $\left(1 \times 10^{7} / \mathrm{ml}\right)$ in HBSS without $\mathrm{Ca}^{2+}$ or $\mathrm{Mg}^{2+}$, were incubated for $15 \mathrm{~min}$ at $23^{\circ} \mathrm{C}$ in the presence of $\mathrm{Zn}^{2+}$ $(50 \mu \mathrm{M})$ and various proportions of ${ }^{125} \mathrm{I}$-labeled and unlabeled HMWK, keeping the total concentration of HMWK constant at 1 $\mu \mathrm{g} / \mathrm{ml}$. Binding of ${ }^{125} \mathrm{I}-\mathrm{HMWK}$ was determined as indicated in Methods and plotted as a fraction of the total that consisted of ${ }^{125} \mathrm{I}$ HMWK and unlabeled HMWK. The plotted data are mean \pm SEM of three experiments.

bated in the presence of mixtures of variable amounts of ${ }^{125} \mathrm{I}$ HMWK and unlabeled HMWK, keeping the total concentration of HMWK constant at $1 \mu \mathrm{g} / \mathrm{ml}$. As the proportion of radiolabeled HMWK to unlabeled HMWK increased, the amount of ${ }^{125} \mathrm{I}-\mathrm{HMWK}$ bound to the neutrophil increased in direct proportion (Fig. 5) with a linear correlation coefficient of $r=0.93$. The slope of 0.85 indicates that the labeled and unlabeled HMWK interacted with the neutrophil surface with similar affinity.

The ability of HMWK to inhibit binding of ${ }^{125} \mathrm{I}-\mathrm{HMWK}$ to neutrophils was also found to be concentration dependent (Fig. 6). Unlabeled HMWK inhibited the binding of ${ }^{125} \mathrm{I}-$

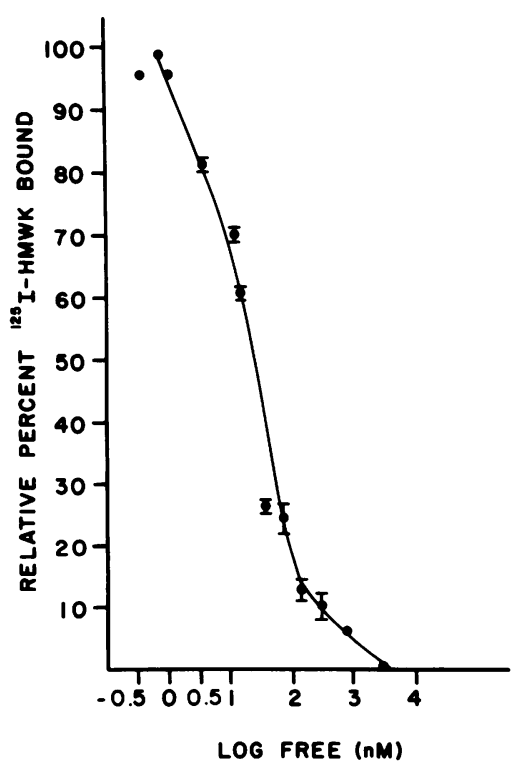

Figure 6. Ability of HMWK to inhibit ${ }^{125}$ IHMWK binding to neutrophils. ${ }^{125} \mathrm{I}$ HMWK $(0.8 \mu \mathrm{g} / \mathrm{ml}$ or $6.55 \mathrm{nM})$ was incubated with isolated neutrophils $\left(10^{7} / \mathrm{ml}\right)$ in HBSS without $\mathrm{Ca}^{2+}$ or $\mathrm{Mg}^{2+}$ containing $50 \mathrm{nM} \mathrm{Zn^{2+ }}$ for $10 \mathrm{~min}$ at $23^{\circ} \mathrm{C}$ in the presence of the indicated log concentration of HMWK given on the abscissa. The mean \pm SEM of each individual data point from three individual experiments are plotted and the line drawn is calculated from the means of the three experiments using a four-parameter

logistic function which fits the values of the ordinate into relative values between 0 and 100\% (29). 
A.

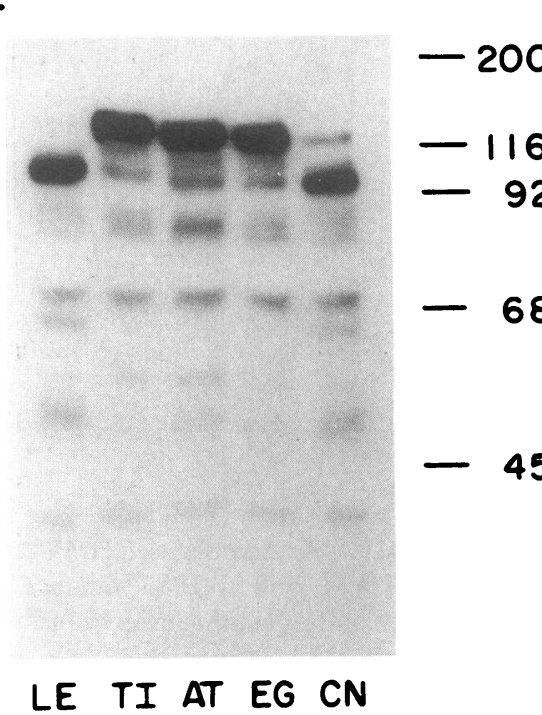

B.

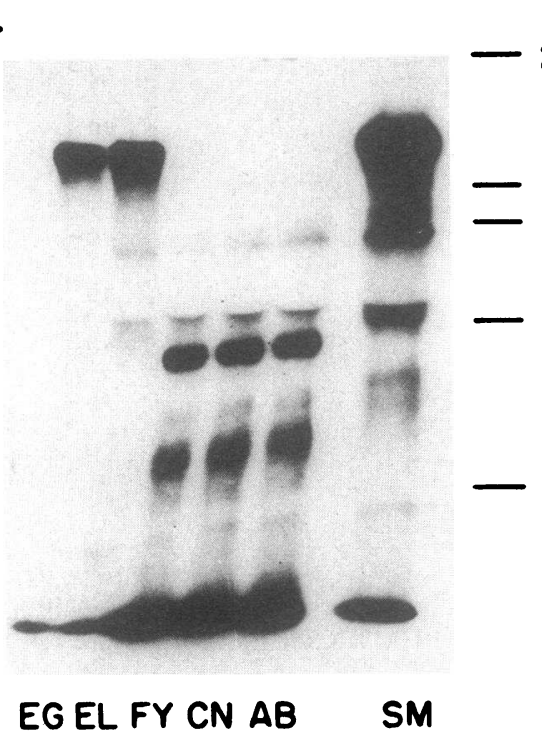

Figure 7. Molecular form of ${ }^{125} \mathrm{I}-$ HMWK bound to neutrophils. ${ }^{125}$ I-HMWK (8.3 nM) was incubated with neutrophils $\left(1 \times 10^{7} /\right.$ $\mathrm{ml}$ ) and $50 \mu \mathrm{M} \mathrm{Zn^{2+ }}$ in the presence or absence of various inhibitors for $20 \mathrm{~min}$ at $23^{\circ} \mathrm{C}$ and centrifuged through an oil mixture for $2 \mathrm{~min}$. The pellet was solubilized in 4\% SDS and run on a $7.5 \%$ PAGE. In $A$, the samples were not reduced before application to the gel. In $B$, the samples were reduced with $2 \% \beta$-mercaptoethanol followed by boiling for $10 \mathrm{~min}$ before application to the gel. The inhibitors present are $(A)$ $0.5 \mathrm{mM}$ leupeptin (LE); $0.1 \mathrm{mM}$ soybean trypsin inhibitor (TI); 3.2 $\mu \mathrm{M} \alpha_{1}$-antitrypsin (AT); $0.5 \mu \mathrm{M}$ eglin (EG) and no inhibitors (CN). (B) $0.5 \mu \mathrm{M}$ eglin (EG); $0.5 \mu \mathrm{M}$

polyclonal antibody to HNE (EL); $1 \mathrm{mM}$ Foy (FY), no inhibitors (CN), $0.5 \mu \mathrm{M}$ unrelated polyclonal antibody (AB) and purified HMWK starting material (SM). The figure is a photograph of an autoradiogram.

HMWK (6.5 nM) to neutrophils with a $50 \%$ inhibitory concentration of $32 \pm 16 \mathrm{nM}$. Using this mean $50 \%$ inhibitory concentration from these experiments, the apparent $K_{\mathrm{i}}$ was calculated to be about $9.6 \mathrm{nM}$ using the formula of Mueller (27). This value for the $K_{\mathrm{i}}$ reflecting inhibition by HMWK of ${ }^{125}$ I-HMWK binding to neutrophils was not significantly different from the mean $K_{\mathrm{i}}$ value of $10.4 \pm 7 \mathrm{nM}$ obtained from calculations from the $\mathrm{IC}_{50}$ from each individual experiment.

The structure of ${ }^{125} \mathrm{I}-\mathrm{HMWK}$ which was bound to the surface of the neutrophil was investigated (Fig. $7 \mathrm{~A}$ ). When ${ }^{125} \mathrm{I}$ HMWK was bound to neutrophils in the absence of serine protease inhibitors and in the presence of leupeptin, the 120kD band of intact ${ }^{125}$ I-HMWK decreased and a new major lower $M_{\mathrm{r}}$ band at $\sim 95 \mathrm{kD}$ appeared. The level of ${ }^{125} \mathrm{I}$-HMWK binding to neutrophils was the same whether or not proteolytic inhibitors were present. The proteolysis of neutrophil-bound HMWK was prevented by adding individual, well-characterized serine proteinase inhibitors to the binding mixture, such as soybean trypsin inhibitor, $\alpha_{1}$-antitrypsin, and eglin (34). These results indicate that the enzyme(s) most likely responsible for the processing of ${ }^{125}$ I-HMWK during the binding reaction was either HNE or cathepsin G. To distinguish which of the two enzymes was responsible for the proteolysis of the ${ }^{125}$ I-HMWK, further experiments were done using either Foy, a specific inhibitor of cathepsin $G$, or a polyclonal antibody against HNE (Fig. 7 B). The ${ }^{125}$ I-HMWK was proteolyzed during the binding reaction when no inhibitors, Foy, or control antibody was present. In contrast, when the neutralizing polyclonal antibody to HNE was present, most of the proteolysis of the ${ }^{125} \mathrm{I}-\mathrm{HMWK}$ was prevented. These data indicated that HNE was responsible for the cleavage of the ${ }^{125}$ I-HMWK during the binding interaction. Further studies indicated that neutrophil cytolysis was not responsible for the availability of the HNE because lactic dehydrogenase levels were not elevated in the washed neutrophil suspensions.

Reversibility and saturability of the binding of ${ }^{125}$ I-HMWK to neutrophils. Binding of ${ }^{125}$ I-HMWK to neutrophils was re- versible (Fig. 8). When a 50-fold molar excess of unlabeled HMWK was added to the binding reaction at 8 and $18 \mathrm{~min}$, rapid dissociation of the bound ligand occurred. At $8 \mathrm{~min} 96 \%$ of the bound ligand was displaced within $1 \mathrm{~min}$, and at $18 \mathrm{~min}$ $93 \%$ of the bound ligand was displaced.

Because binding of ${ }^{125}$ I-HMWK to neutrophils was specific and reversible, studies were performed under equilibrium conditions to determine if binding was saturable. The number and affinity of ${ }^{125}$ I-HMWK binding sites on neutrophils were determined as a function of ${ }^{125} \mathrm{I}$-HMWK concentration. Increasing concentrations of ${ }^{125} \mathrm{I}$-HMWK were added to neutrophils in the absence or presence of a 50-fold molar excess of unlabeled ligand (Fig. 9). This figure is one representative experiment of three. As the concentration of added ${ }^{125}$ I-HMWK increased, the level of binding increased until it leveled off at $\sim 3.5 \mu \mathrm{g} / \mathrm{ml}(29 \mathrm{nM})$ of the added ${ }^{125} \mathrm{I}$-HMWK (Fig. 9, left). Using the graphical method of Scatchard (30), a saturable binding site was characterized to be one of the high affinity with an apparent $K_{\mathrm{d}}$ of $9 \mathrm{nM}$ and 40,000 sites per cell (Fig. 9, right). This value from one experiment is similar to two other experiments, which together had a mean apparent $K_{\mathrm{d}}$ of $10 \pm 1.3 \mathrm{nM}$ and $48,000 \pm 17,000$ sites per cell. Confirmation of

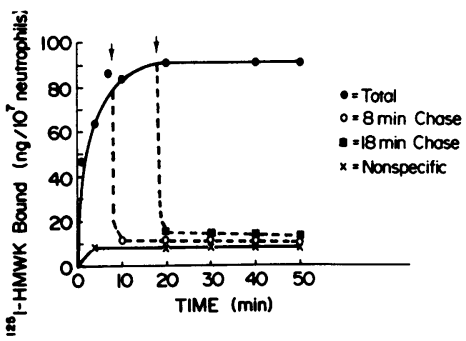

Figure 8. Reversibility of ${ }^{125}$ I-HMWK binding to neutrophils. Isolated neutrophils $\left(10^{7} / \mathrm{ml}\right)$ in HBSS without $\mathrm{Ca}^{2+}$ or $\mathrm{Mg}^{2+}$ were incubated at $23^{\circ} \mathrm{C}$ in the presence of $\mathrm{Zn}^{2+}(50 \mu \mathrm{M})$ and ${ }^{125} \mathrm{I}-\mathrm{HMWK}(1 \mu \mathrm{g} / \mathrm{ml})$. (•) represents total binding. At $8 \mathrm{~min}(0)$ and $18 \mathrm{~min}$

(घ) a 50-fold molar excess of unlabeled HMWK was added. The binding was determined at the indicated time points as described in Methods. The plotted data are the mean of two experiments and represent total binding. Nonspecific binding $(X)$ is also plotted. 


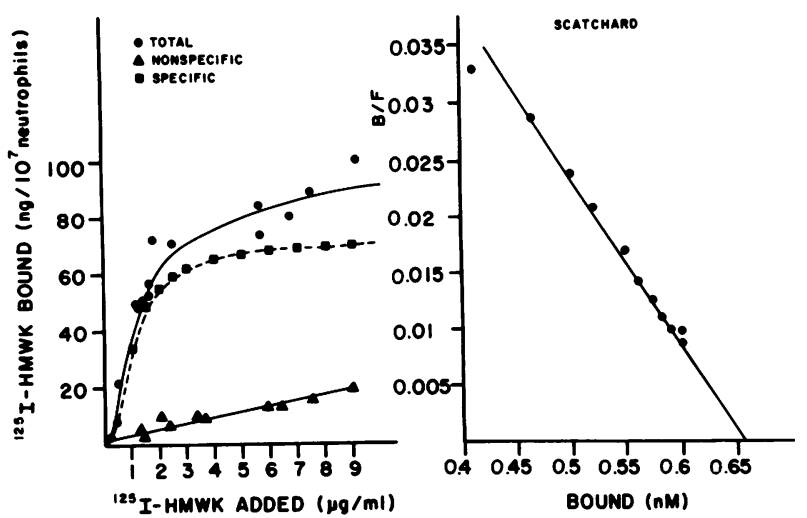

Figure 9. Concentration-dependent binding of ${ }^{125} \mathrm{I}-\mathrm{HMWK}$ to neutrophils. Neutrophils $\left(1 \times 10^{7} / \mathrm{ml}\right)$ in $\mathrm{HBSS}$ without $\mathrm{Ca}^{2+}$ or $\mathrm{Mg}^{2+}$ were incubated with increasing concentrations of ${ }^{125} \mathrm{I}-\mathrm{HMWK}$ in the presence of $\mathrm{Zn}^{2+}(50 \mu \mathrm{M})$ at $23^{\circ} \mathrm{C}$ for $15 \mathrm{~min}$. Binding of ${ }^{125} \mathrm{I}$ HMWK to neutrophils was determined as indicated in Methods. In the panel on the left, total binding (•) and nonspecific binding ( $\Delta$ ) were directly determined and specific binding ( $\boldsymbol{(})$ was calculated by subtracting nonspecific binding from total binding. This figure is a representative experiment of three, performed identically. (Right) "Scatchard", the "best-fit" data of the ratio of bound/free versus bound (in nanomolar), as determined by linear regression analysis of the data (left) is plotted.

this interpretation of the graphical representation of the experimental data was obtained by computer analysis of the same experimental data $(31,32)$. Using a one site model for calculating the data for three experiments, a high affinity binding site with an apparent $K_{\mathrm{d}}$ of $18.0 \pm 2.6 \mathrm{nM}($ mean $\pm \mathrm{SD})$ and $70,000 \pm 25,000$ molecules per cell (mean \pm SD) was described.

Role of HMWK in HNE secretion in plasma. Further studies were performed to determine if HMWK has a role in HNE secretion. 10,000,000 normal human neutrophils were resuspended and preincubated for either $30 \mathrm{~s}$ or $30 \mathrm{~min}$ in normal plasma followed by recalcification for $60 \mathrm{~min}$. Normal neutrophils released $1.08 \mu \mathrm{g} / \mathrm{ml} \mathrm{HNE}$ after $30 \mathrm{~s}$ and $0.7 \mu \mathrm{g} / \mathrm{ml} \mathrm{HNE}$, respectively after $30 \mathrm{~min}$ preincubation (Fig. 10, bar $A$ ). In four separate experiments, normal neutrophils resuspended in total kininogen-deficient plasma released virtually identical amounts of HNE when compared with the same neutrophils resuspended in normal plasma after $30 \mathrm{~s}$ preincubation (data not shown). In contrast, the extent of HNE secretion from HMWK-deficient neutrophils suspended in total kininogendeficient plasma was $0.4 \mu \mathrm{g} / \mathrm{ml} \mathrm{HNE}$ when preincubated for $30 \mathrm{~s}$ and $0.43 \mu \mathrm{g} / \mathrm{ml} \mathrm{HNE}$ for $30 \mathrm{~min}$. (Fig. 10, bar $B$ ). The release of HNE from HMWK-deficient neutrophils suspended in normal plasma was $0.42 \mu \mathrm{g} / \mathrm{ml} \mathrm{HNE}$ when preincubated for $30 \mathrm{~s}$ but became normal, $0.98 \mu \mathrm{g} / \mathrm{ml} \mathrm{HNE}$, when preincubated for $30 \mathrm{~min}$. (Fig. 10, bar $C$ ). These results suggest that HMWK bound to the neutrophil surface from plasma could contribute to HNE secretion and that neutrophil HMWK could also serve the same function.

Role of HMWK in neutrophil activation in a plasma-free system. Normal neutrophils stimulated with purified human plasma kallikrein $(0.2 \mathrm{U} / \mathrm{ml})$ released $16.6 \pm 8 \%$ of the total HNE and induced an initial rate of aggregation that was $36 \%$ of that which was induced by FMLP $(0.2 \mu \mathrm{M})$. Alternatively, HMWK-deficient neutrophils stimulated with human PK $(0.2$ $\mathrm{U} / \mathrm{ml}$ ) released only $2.5 \%$ of the total HNE and induced an initial rate of aggregation that was $8 \%$ of that which was in- duced by FMLP $(0.2 \mu \mathrm{M})$ (Table II). These results confirm the importance of neutrophil HMWK in the absence of plasma HMWK.

\section{Discussion}

The demonstration that HMWK specifically binds to the surface of human neutrophils suggests that neutrophils contain unoccupied sites for the expression of HMWK. The amount of ${ }^{125}$ I-HMWK that binds to neutrophils is equivalent at 0,23 , and $37^{\circ} \mathrm{C}$, and remains constant over a 50 -min incubation period (Fig. 3). In addition, the binding of ${ }^{125} \mathrm{I}-\mathrm{HMWK}$ is completely reversible (Fig. 8). Both of these studies suggest that the HMWK associated with neutrophil lysates (Fig. 1) does not result from internalization of plasma HMWK by a putative receptor-ligand complex. Further studies showed that neutrophil HMWK was not plasma HMWK tightly bound and nonexchangeable with the neutrophil surface. Additional studies are needed with neutrophil progenitors to show if they serve as the biosynthetic source of neutrophil HMWK.

Demonstration that ${ }^{125} \mathrm{I}-\mathrm{HMWK}$ binds to the surface of neutrophils indicates a means whereby HMWK from either plasma or neutrophils might be placed in a position such that it could influence the interaction of kallikrein with neutrophils. The specificity of binding of ${ }^{125}$ I-HMWK to neutrophils is shown using various approaches. Radiolabeled HMWK competes with equal affinity with unlabeled HMWK for neutrophil binding (Fig. 5) and excess unlabeled HMWK completely inhibits binding of ${ }^{125}$ I-HMWK to neutrophils (Fig. 6). In addition, only unlabeled HMWK, not Factor V, Factor XII, PK or FNDPs is able to prevent the binding of ${ }^{125}$ I-HMWK to the surface of the neutrophil (Table I).

Although ${ }^{125} \mathrm{I}-\mathrm{HMWK}$ can bind to neutrophils in an intact form, neutrophil-bound ${ }^{125}$ I-HMWK undergoes proteolysis (Fig. 7). The proteolysis of neutrophil-bound ${ }^{125}$ I-HMWK is prevented by inhibitors of serine proteinases, such as soybean trypsin inhibitor, eglin, and $\alpha_{1}$-antitrypsin but not by leupeptin, a cysteine proteinase inhibitor. Because proteolysis of ${ }^{125} \mathrm{I}$ HMWK is inhibited by a polyclonal antibody directed toward HNE and not by Foy, a specific inhibitor of cathepsin G, HNE appears to be the enzyme responsible for the proteolysis of neutrophil bound ${ }^{125} \mathrm{I}-\mathrm{HMWK}$. HNE is an azurophilic granule protease that is released by many neutrophil agonists. The presence of HNE activity on or about the surface of the neutrophil is most likely due to stimulation during preparation of washed neutrophils. Cytolysis is not responsible since lactic dehydrogenase levels were undetectable in neutrophil suspension media. Whether the binding of HMWK per se to the

Table II. Role of HMWK in HNE Secretion by Kallikrein

\begin{tabular}{lcc}
\hline & \% Total HNE activity & \% of aggregation \\
\hline Control neutrophils & $16.6 \pm 8.0$ & 36 \\
HMWK-deficient neutrophils & 2.5 & 8 \\
\hline
\end{tabular}

Neutrophils were stimulated with purified human plasma kallikrein $(0.2 \mathrm{U} / \mathrm{ml})$ as described in Methods. FMLP $(0.2 \mu \mathrm{M})$ stimulation of normal neutrophils induced an initial rate of aggregation, which was defined as $100 \%$. The supernatants of neutrophils are assessed for total HNE activity using the chromogenic substrate methoxysuccinyl-Ala-Ala-Pro-Val-pNA. 
neutrophils causes activation is unknown. The binding of ${ }^{125} \mathrm{I}$ HMWK to the neutrophil surface does not require prior proteolysis; the amount of ${ }^{125}$ I-HMWK bound is equivalent whether or not protease inhibitors are present.

Binding of ${ }^{125} \mathrm{I}-\mathrm{HMWK}$ to neutrophils requires the presence of $\mathrm{Zn}^{2+} . \mathrm{Ca}^{2+}$ alone is not able to support binding of ${ }^{125}$ I-HMWK to neutrophils, nor does it potentiate binding when $\mathrm{Zn}^{2+}$ is present (Fig. 4). The same findings were observed with $\mathrm{Mg}^{2+}$. Therefore, the binding of ${ }^{125}$ I-HMWK to neutrophils is similar to the requirements for binding of ${ }^{125} \mathrm{I}-\mathrm{HMWK}$ to platelets and human umbilical vein endothelial cells in that $\mathrm{Zn}^{2+}$ is the only divalent cation that is essential $(16,35)$. This observation, as well as the fact that $\mathrm{Zn}^{2+}$ has not been reported to be essential for binding of other proteins to the platelet, endothelial cell or neutrophil surface supports the postulate that the effect of $\mathrm{Zn}^{2+}$ is on the HMWK molecule itself. Human and rat HMWK (36), but not their heavy chain, specifically bind to $\mathrm{Zn}^{2+}$ affinity columns. The observation has also been made that $50 \mu \mathrm{M} \mathrm{Zn}^{2+}$ induces a conformational change of bovine HMWK and its light chain as measured by scanning absorption spectrophotometry (37).

Binding of ${ }^{125}$ I-HMWK to neutrophils is $>90 \%$ reversible at 8 and $18 \mathrm{~min}$ (Fig. 8). The binding is characterized by one high-affinity, saturable site with an apparent $K_{\mathrm{d}}$ of $18.0 \pm 1.5$ $\mathrm{nM}$ by computer fitting of the experimental points from three experiments (Fig. 9). The estimated $K_{\mathrm{i}}$ computed from the midpoints of the competition inhibition curves from three experiments (Fig. 6) (27) is found to be similar at $10.4 \pm 4.0 \mathrm{nM}$.

Our studies (Fig. 2) show that unstimulated neutrophils do not have detectable HMWK on their surfaces. The functional significance of binding of HMWK to neutrophils is not yet fully delineated. Other peptides and proteins that bind to the neutrophil surface elicit responses from the neutrophil resulting in chemotaxis, aggregation, degranulation, and the respiratory burst. Kallikrein has been shown to result in neutrophil chemotaxis (4), aggregation (5) and degranulation (6). Because prekallikrein circulates in plasma complexed with HMWK $(2$, 3 ), the ability of kallikrein to interact with neutrophils may result from the binding of the enzyme to the neutrophil surface in the presence of HMWK. The inability of $\beta$-kallikrein, which contains an additional cleavage in the heavy chain, to cause neutrophil activation (38) and the imparied cleavage of HMWK by $\beta$-kallikrein are consistent with this possibility since the heavy chain of kallikrein contains the binding region for HMWK (39).

HMWK from either plasma or neutrophils appears to be a cofactor for HNE secretion from neutrophils (Fig. 10). The finding that HMWK-deficient neutrophils suspended in total kininogen-deficient plasma had a reduced level of HNE secretion at $30 \mathrm{~s}$ and $\mathbf{3 0}$ min indicates a specific function of neutrophil HMWK in the mechanism of HNE secretion. Our previous studies (8) show that plasma kallikrein plays a role in the secretion of HNE. Because the release of HNE by purified kallikrein from HMWK-deficient neutrophils is only $15 \%$ compared with normal neutrophils (Table II), we suggest that HMWK may serve as an acquired receptor for plasma kallikrein.

Our studies also demonstrate that HMWK is proteolyzed after binding to the surface of neutrophils. The proteolysis of HMWK by HNE may regulate the extent of the association of HMWK with neutrophils. Proteolysis of a bound ligand to neutrophils is not unique to HMWK. Cationic proteins identified as enzymes from the primary granules impair the che-

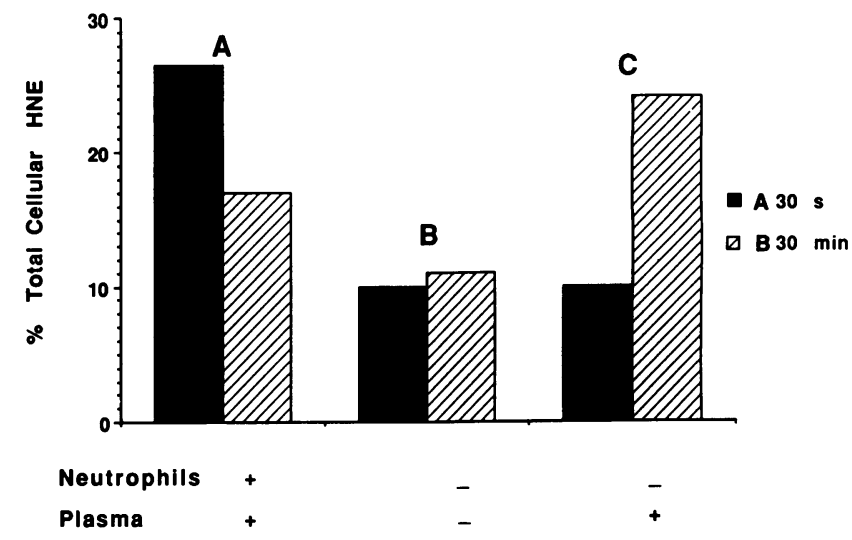

Figure 10. Effect of plasma and neutrophil HMWK on HNE secretion. Normal human neutrophils $\left(1 \times 10^{7} / \mathrm{ml}\right)$ were resuspended in $(A)$ normal human plasma and HMWK-deficient neutrophils (1 $\times 10^{7} / \mathrm{ml}$ ) were resuspended in $(C)$ normal human or $(B)$ total kininogen-deficient plasma. After $30 \mathrm{~s}$ or $30 \mathrm{~min}$ preincubations, the cell suspension in plasma in polypropylene tubes were recalcified at $23^{\circ} \mathrm{C}$ by the addition of $30 \mathrm{mM} \mathrm{CaCl}_{2}$. At 60 -min aliquots from each cell suspension were removed and centrifuged at $13,000 \mathrm{~g}$ for $5 \mathrm{~min}$. HNE antigen was assayed by competitive ELISA (33). Each HNE measurement was performed in duplicate and the means are graphed. The coefficient of variation of the ELISA for HNE is $10 \%$ (43).

motactic response stimulated by $\mathrm{C} 5 \mathrm{a}(40)$. A serine-dependent protease has been shown to hydrolyze formyl-methionyl oligopeptides (41). Kleniewski and Donaldson recently reported that HNE cleaves HMWK into lower molecular weight fragments, destroying the coagulant properties of HMWK contained within its light chain, without releasing kinin (42). This observation and our data both imply that once kallikrein activates neutrophils to secrete HNE, the released HNE may hydrolyze HMWK and decrease its cofactor activity.

\section{Acknowledgments}

We would like to thank Anthony Farber for the competitive ELISA determinations of HMWK and Ms. Cathy Spiotta and Ms. Rita Stewart for their expert preparation of the manuscript.

This work has been supported in part by National Heart, Lung, and Blood Institute grants HL-24365 (to R. W. Colman), HL-19055 (to R. W. Colman and Y. T. Wachtfogel), and HL-35553 (to A. H. Schmaier), a National American Heart Association Grant-In-Aid 861169 (to A. H. Schmaier), a grant from the March of Dimes Birth Defects Foundation (to A. H. Schmaier), a grant from the Cystic Fibrosis Foundation (to Y. T. Wachtfogel), an American Lung Association of Pennsylvania Research Grant (to Y. T. Wachtfogel), and a grant from the Ben Franklin Partnership of the State of Pennsylvania. Dr. Schmaier is a recipient of a Research Career Development Award (HL-01615) and Dr. Gustafson received a National Research Service Award (HL-06940).

\section{References}

1. Scott, C. F., L. D. Silver, M. Schapira, and R. W. Colman. 1984. Cleavage of human high molecular weight kininogen markedly enhances its coagulant activity. Evidence that this molecule exists as a procofactor. J. Clin. Invest. 73:954-962.

2. Mandle, R. Jr., R. W. Colman, and A. P. Kaplan. 1976. Identification of prekallikrein and high molecular weight kininogen as a complex in human plasma. Proc. Natl. Acad. Sci. USA. 73:4179-4183.

3. Scott, C. F., and R. W. Colman. 1980. Function and immuno- 
chemistry of prekallikrein-high molecular weight kininogen complex in plasma. J. Clin. Invest. 65:413-421.

4. Silverberg, M., J. E. Nicoll, and A. P. Kaplan. 1980. The mechanism by which the light chain of cleaved HMW-kininogen augments the activation of prekallikrein, factor XI and Hageman factor. Thromb. Res. 20:173-189.

5. Thompson, R. E., R. Mandle, Jr., and A. P. Kaplan. 1979. Studies of binding of prekallikrein and Factor XI to high molecular weight kininogen and its light chain. Proc. Natl. Acad. Sci. USA. 76:4862-4866.

6. Kaplan, A. P., A. B. Kay, and K. F. Austen. 1972. A prealbumin activator of prekallikrein. III. Appearance of chemotactic activity for human neutrophils. J. Exp. Med. 135:81-97.

7. Shapira, M., E. Despland, C. F. Scott, L. A. Boxer, and R. W. Colman. 1972. Purified human plasma kallikrein aggregates human blood neutrophils. J. Clin. Invest. 69:1199-1201.

8. Wachtfogel, Y. T., U. Kucich, H. L. James, C. F. Scott, M. Schapira, M. Zimmerman, A. B. Cohen, and R. W. Colman. 1983. Human plasma kallikrein releases neutrophil elastase during blood coagulation. J. Clin. Invest. 72:1672-1677.

9. Williams, L. T., R. Snyderman, M. C. Pike, and R. J. Lefkowitz. 1977. Specific receptor sites for chemotactic peptides on human polymorphonuclear leukocytes. Proc. Natl. Acad. Sci. USA. 74:1204-1208.

10. Chenoweth, D. E., and T. E. Hugli. 1978. Demonstration of a specific C5a receptor on intact human polymorphonuclear leukocytes. Proc. Natl. Acad. Sci. USA. 75:3943-3947.

11. Tracy, P. B., J. M. Peterson, M. E. Nesheim, F. C. McDuffie, and K. G. Mann. 1979. Interaction of coagulation factor $V$ and factor Va with platelets. J. Biol. Chem. 254:10354-10361.

12. Schmaier, A. H., A. Zuckerberg, C. Silverman, J. Kuchibhotla, G. P. Tuszynski, and R. W. Colman. 1983. High molecular weight kininogen. A secreted platelet protein. J. Clin. Invest. 71:1477-1489.

13. Kerbiriou-Nabias, D. M., F. O. Garcia, and M.-J. Larrieu. 1984. Radioimmunoassays of human high and low molecular weight kininogens in plasma and platelets. Br. J. Haematol. 56:273-286.

14. Schmaier, A. H., P. M. Smith, A. D. Purdon, J. G. White, and R. W. Colman. 1986. High molecular weight kininogen: localization in unstimulated and activated platelets and activation by a platelet calpain(s). Blood. 67:119-130.

15. Greengard, J. S., and J. H. Griffin. 1984. Receptors for high molecular weight kininogen on stimulated washed human platelets. Biochemistry. 23:6863-6869.

16. Gustafson, E. J., D. Schutsky, L. C. Knight, and A. H. Schmaier. 1986. High molecular weight kininogen binds to unstimulated platelets. J. Clin. Invest. 78:310-318.

17. Kerbiriou, D. M., and J. H. Griffin. 1979. Human high molecular weight kininogen. Studies of structure-function relationships and of proteolysis of the molecule occurring during contact activation of plasma. J. Biol. Chem. 254:12020-12027.

18. Laemmli, U. K. 1970. Cleavage of structural proteins during the assembly of the head of bacteriophage T45. Nature (Lond.). 227:680-685.

19. Fraker, P. J., and S. C. Speck, Jr. 1978. Protein and cell membrane iodinations with a sparingly soluble chloroamide 1,3,4,6-tetrachloro-3 alpha, 6 alpha-diphenylglycoluril. Biochem. Biophys. Res. Commun. 80:849-857.

20. Freise, J. 1985. Gabexate mesilate and camostate: new inhibitors of phospholipase $A_{2}$ and their influence on the alpha-amylase activity in serum of patients with acute pancreatitis. Clin. Biochem. 4:224-229.

21. James, H. L., Y. T. Wachtfogel, P. L. James, M. Zimmerman, R. W. Colman, and A. B. Cohen. 1985. A unique elastase in human blood platelets. J. Clin. Invest. 76:2330-2337.

22. Baugh, R. J., and J. Travis. 1976. Human leukocyte granule elastase: rapid isolation and characterization. Biochemistry. 15:836841.

23. Colman, R. W., A. Bagdasarian, R. C. Talamo, C. F. Scott, M.
Sevy, J. A. Guimares, J. V. Pierce, and A. P. Kaplan. 1975. Williams trait. Human kininogen deficiency with diminished levels of plasminogen proactivator and prekallikrein associated with abnormalities of the Hageman-dependent pathways. J. Clin. Invest. 56:1650-1662.

24. Castillo, M. J., K. Nakajima, M. Zimmerman, and J. C. Powers. 1979. Sensitive substrates for human leukocyte and porcine pancreatic elastase. A study of the merits of various chromophoric and fluoregenic leaving groups in assays for serine proteases. Anal. Biochem. 99:53-64.

25. Barrett, A. J. 1981. Cathepsin G. Methods Enzymol. 80:561565.

26. Wroblewski, F. and J. S. Ladue. 1955. Lactic dehydrogenase activity in blood. Proc. Soc. Exp. Biol. Med. 90:210-213.

27. Mueller, R. 1983. Determination of affinity and specificity of anti-Hapten antibodies by competitive radioimmunoassay. Methods Enzymol. 92:589-601.

28. Schmaier, A. J., D. Schutsky, A. Farber, L. D. Silver, H. N. Bradford, and R. W. Colman. 1987. Determination of the bifunctional properties of high molecular weight kininogen by studies with monoclonal antibodies directed to each of its chains. J. Biol. Chem. 262:1405-1411.

29. Canellas, P. F., and A. E. Karu. 1981. Statistical package for analysis of competitive ELISA results. J. Immunol. Methods. 47:375385.

30. Scatchard, G. 1949. The attraction of proteins for small molecules and ions. Ann. NY Acad. Sci. 51:660-672.

31. Munson, P. J., and D. Rodbard. 1980. LIGAND: a versatile computerized approach for characterization of ligand-binding systems. Anal. Biochem. 107:220-239.

32. Brass, L. F. and S. J. Shattil. 1982. Changes in surface-bound and exchangeable calcium during platelet activation. J. Biol. Chem. 257:14000-14005.

33. Wachtfogel, Y. T., R. A. Pixley, U. Kucich, W. Abrams, G. Weinbaum, M. Schapira, and R. W. Colman. 1986. Purified plasma Factor XIIa aggregates human neutrophils and causes degranulation. Blood. 67:1731-1737.

34. Seemuller, U., H. Fritz, and M. Eulitz. 1981. Eglin: ElastaseCathepsin G inhibitor from leeches. Methods Enzymol. 80:804-815.

35. Schmaier, A. H., A. Kuo, D. Lundberg, S. Murray, and D. Cines. 1988. The expression of high molecular weight kininogen on human endothelial cells. J. Biol. Chem. 263:16,327-16,333.

36. Hayashi, I., H. Kato, S. Iwanaga, and S. Oh-ishi. 1985. Rat plasma high molecular weight kininogen. J. Biol. Chem. 260:61156123.

37. Shimada, T., H. Kato, and S. Iwanaga. 1984. Effect of metal ions on the surface-mediated activation of factor XII and prekallikrein. Adv. Exp. Med. Biol. Vol. 198.

38. Colman, R. W., Y. Wachtfogel, U. Kucich, G. Weinbaum, S. Hahn, R. A. Pixley, C. F. Scott, A. de Agostini, D. Burger, and M. Schapira. 1985. Effect of cleavage of the heavy chain of human plasma kallikrein on its functional properties. Blood. 65:311-318.

39. Van der Graaf, F., G. Tans, B. N. Bouma, and J. H. Griffin. 1982. Isolation and functional properties of the heavy and light chains of human plasma kallikrein. J. Biol. Chem. 257:14300-14305.

40. Wright, D. G., and J. I. Gallin. 1977. A functional differentiation of human neutrophil granules: Generation of C5a by a specific (secondary) granule product and inactivation of $\mathrm{C5a}$ by azurophilic (primary) granule products. J. Immunol. 119:1068-1076.

41. Aswanikumar, S., E. Schiffmann, B. A. Corcoran, and S. M. Whal. 1976. Role of a peptidase in phagocyte chemotaxis. Proc. Natl. Acad. Sci. USA. 73:2439-2442.

42. Kleniewski, J., and V. H. Donaldson. 1988. Granulocyte elastase cleaves high molecular weight kininogen and destroys its clot-promoting activity. J. Exp. Med. 167:1895-1907.

43. Kucich, U., W. R. Abrams, and H. L. James. 1980 . Solid phase immunoassay of dog neutrophil elastase. Anal. Biochem. 109:403409. 